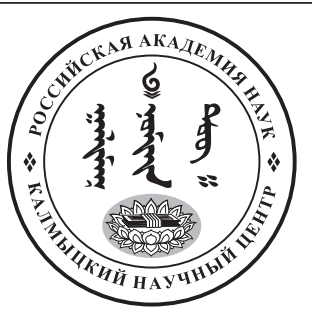

Published in the Russian Federation

Oriental Studies (Previous Name: Bulletin of the Kalmyk Institute

for Humanities of the Russian Academy of Sciences)

Has been issued as a journal since 2008

ISSN: 2619-0990; E-ISSN: 2619-1008

Vol. 13, Is. 3, pp. 688-695, 2020

DOI: $10.22162 / 2619-0990-2020-49-3-688-695$

Journal homepage: https://kigiran.elpub.ru

УДК 316.4

DOI: 10.22162/2619-0990-2020-49-3-688-695

\title{
Опыт трудовой миграции сельских жителей Калмыкии (по результатам глубинных интервью)
}

\author{
Ноган Вячеславовна Бадмаева ${ }^{1}$ \\ ${ }^{1}$ Калмыцкий научный центр РАН (д. 8, ул. им. И. К. Илишкина, 358000 Элиста, Российская Феде- \\ рация) \\ научный сотрудник
}

iD 0000-0002-4799-5506. E-mail: badmaevanv@kigiran.com

\author{
(C) КалмНЦ РАН, 2020 \\ (C) Бадмаева Н. В., 2020
}

\begin{abstract}
Аннотация. Введение. Трудовая миграция сельского населения Калмыкии является актуальной проблемой региона. Перманентный характер и длительность экономического кризиса в аграрной сфере республики отрицательно сказались на уровне жизни сельских жителей. Отсутствие работы, низкие зарплаты вынуждают сельское население Калмыкии самостоятельно решать проблемы собственного трудоустройства путем миграции в столицу республики или за ее пределы. Цель данного исследования - проанализировать миграционный опыт трудового мигранта из сельской местности Республики Калмыкия. Материалы и методы. Исследование проводилось методом глубинного структурированного интервью. Применение качественных методов в изучении трудовой миграции позволяет анализировать эту проблему с точки зрения отдельных участников миграционных процессов, их судеб и личной жизненной истории. Результаты. Выявлено, что одним из экономических факторов миграции является необходимость оплачивать ипотеку или потребительские кредиты. Миграционные циклы тесно соотносятся с важнейшими этапами жизненного цикла - женитьбой, разводом, рождением детей, женитьбой сыновей или выдачей замуж дочерей. Для части респондентов решение о миграции связано с определенными этапами взросления детей. Миграции формируют новый контекст семейно-брачных отношений: браки приобретают признаки «гостевого брака», в семье меняются гендерные роли, например, когда на заработки уезжает женщина. Трансформируется или подменяется роль бабушек или дедушек, зачастую выполняющих функции выехавшего родителя. Значительное влияние приобретают горизонтальные социальные сети: земляческие и родственные отношения. Опыт работы на выезде становится инструментом экономической стратегии и мобильности - люди покупают жильё в городе, используют заработанные деньги для помощи в реализации жизненных планов детей. Миграция родителей становится ориентиром для будущих миграций их детей. Полученные результаты позволяют фиксировать в социальном профиле сельских трудовых мигрантов активных личностей, высоко мотивированных к труду, сочетающих стремление к достойному уровню жизни с умением приспосабливаться к напряженным условиям труда и быта в отрыве от дома и семьи.
\end{abstract}


Ключевые слова: трудовая миграция, сельское население, биографический метод, глубинное интервью, Республика Калмыкия

Благодарность. Исследование проведено в рамках госзадания КалмНЦ РАН «Развитие сельских территорий Юга России: комплексный социально-экономический и экологический мониторинг» (Рег. № НИОКТР АААА-А19-1190111490037-8).

Для цитирования: Бадмаева Н. В. Опыт трудовой миграции сельских жителей Калмыкии (по результатам глубинных интервью) // Oriental studies. 2020. T. 13. № 3. С. 688-695. DOI: 10.22162/2619-0990-2020-49-3-688-695

UDC 316.4

DOI: $10.22162 / 2619-0990-2020-49-3-688-695$

\title{
Labor Migration of Kalmykia's Rural Residents: a Case Study of In-Depth Interviews
}

\author{
Nogan V. Badmaeva ${ }^{1}$ \\ ${ }^{1}$ Kalmyk Scientific Center of the RAS (8, Ilishkin St., Elista 358000, Russian Federation) \\ Research Associate
}

iD 0000-0002-4799-5506. E-mail: badmaevanv@kigiran.com

(C) KalmSC RAS, 2020

(C) Badmaeva N. V., 2020

\begin{abstract}
Introduction. Labor migration of Kalmykia's rural population is a pressing challenge for the region. Permanent nature and endurance of the socioeconomic crisis in the agricultural sector of the republic have been adversely affecting the living standards of ordinary villagers. Lack of work opportunities and low salaries result in that the latter migrate en masse to the regional capital and even further. Goals. The study aims to analyze labor migration experiences of local rural dwellers. Materials and Methods. The paper summarizes a number of in-depth structured interviews. The qualitative research methods employed make it possible to view the issue in the eyes of unrelated actual participants of the migration processes, with certain attention paid to their backgrounds and life paths. Results. The work reveals one of the key economic factors underlying labor migration is the necessity to pay mortgage and consumer loans. And migration waves closely align with individual life cycles, such as marriage, divorce, births and even weddings of children. Some respondents reported their migrations were determined by certain adulthood stages of children. All these aspects give rise a new context of family and marriage relations: there emerge guest marriage patterns and changes in gender roles, e.g., in some families those are women who act as migrant workers. Roles of grandparents experience transformations forcing the latter to assume functions of the absent father of mother. Horizontal social networks come to the fore, including territorial and kindred ties. Such migrant labor experiences become a tool of economic strategies and mobility: people purchase dwellings in the city, and support children funding their plans with the earned money. So, migration of parents definitely serves a landmark for future migrations of their descendants. The results obtained attest to that the social profile of rural labor migrants contains quite a share of active individuals intensely motivated to work, ones who strive for better living standards and can adjust themselves to strenuous living / working conditions staying away from home and family.

Keywords: labor migration, rural population, biographical method, in-depth interview, Republic of Kalmykia

Acknowledgements. The reported study was funded by government subsidy — project of Kalmyk Scientific Center of the RAS 'Development of Rural Territories of Southern Russia: Comprehensive Socioeconomic and Environmental Monitoring' (state reg. nо. НИОКТР ААААA19-1190111490037-8).

For citation: Badmaeva N. V. Labor Migration of Kalmykia's Rural Residents: a Case Study of In-Depth Interviews. Oriental Studies. 2020. Vol. 13(3): 688-695. (In Russ.). DOI: 10.22162/26190990-2020-49-3-688-695
\end{abstract}




\section{Введение}

Кризисное состояние сельскохозяйственной отрасли и ее медленная модернизация в стране в целом отрицательно сказались на экономике многих регионов. Не является исключением и Республика Калмыкия, где сельское хозяйство является одной из главных отраслей экономики. Отсутствие крупных сельскохозяйственных предприятий, сложное положение личных подсобных хозяйств привели к снижению уровня жизни сельского населения республики, уменьшению возможностей устроиться на работу, массовой миграции в города, мегаполисы, другие более развитые регионы. Ухудшают положение сельских жителей и проблемы разрушения сельской социальной инфраструктуры: закрываются школьные и дошкольные учреждения, учреждения культуры, отмечается неудовлетворенность населения медицинским обслуживанием и многое другое.

В этой связи одной из актуальных проблем региона является миграционный отток сельского населения. В основном это трудовая миграция, поскольку отсутствие работы, низкие зарплаты вынуждают сельское население Калмыкии самостоятельно решать проблемы собственного трудоустройства.

Цель исследования - проанализировать миграционный опыт трудового мигранта из сельской местности Республики Калмыкия.

Опубликовано значительное количество работ, посвященных проблемам трудовой миграции, ее экономическим и демографическим характеристикам, вопросам государственного регулирования трудовых ресурсов страны и многому другому. Однако подобные обобщающие работы не могут удовлетворить потребность исследователей во внимании к деталям, поскольку не фиксируют и не описывают ситуации с точки зрения отдельных участников миграционных процессов, их судеб и личной жизненной истории.

Социальные процессы почти всегда требуют взгляда с «двух сторон», поэтому во многих социологических исследованиях все чаще используется комплексный подход с применением количественных и качествен- ных методов. Классическим социологическим трудом по изучению миграционных процессов на основе применения качественных методов является работа У. Томаса и Ф. Знанецкого «Польский крестьянин в Европе и Америке», в которой предпринят анализ последствий миграции и адаптации мигрантов [Блинова 2011: 172].

В этом и многих других исследованиях использовался биографический метод. И. В. Соснина отмечает, что биографический метод в исследовании миграции обладает широким потенциалом для изучения миграционных процессов. По ее мнению, мигрант как носитель первичной информации, излагая историю своей жизни, приоткрывает завесу своей повседневной жизни для исследователя, дает возможность взглянуть на процесс миграции «изнутри» [Coснина 2012].

По мнению 3. Т. Голенковой и П. Е. Сушко, биографический анализ позволяет реконструировать миграционный путь на уровне индивидов с захватом реальных причин, мотивов и факторов, влияющих на их перемещения. В этом ключе миграционные биографии представляют определенные наслоения жизненных практик и индивидуальных образцов поведения (удачной или неудачной карьеры, успешных или неуспешных браков, жизненных стратегий и т. д.), которые путем наследуемого социального опыта и изменения социального времени приобретают новые наполнения и смыслы. Это необходимо для понимания причин миграции, изучения связи между индивидуальным сознанием и особенностями социальных, культурных, материальных структур, в пределах которых функционируют индивиды [Голенкова, Сушко 2016: 98].

\section{Материалы и методы}

Исследование проводилось методом глубинного структурированного интервью. Поиск респондентов осуществлялся по методу «снежного кома». Всего было проведено 10 интервью. Интервью были проведены в мае 2020 г. Для сохранения анонимности опрашиваемых имена респондентов даны инициалами. Анкета предполагает анализ 
ответов по следующим индикаторам: форма трудовой миграции (сезонная, временная или безвозвратная), длительность нахождения в трудовой миграции, профессиональный статус в трудовой миграции, родственные контакты, землячества, влияние образования на миграцию, семейные стратегии, влияние на семейно-брачные отношения, социальная мобильность (повышается ли социальный статус), возвращение или невозвращение в сельское поселение, откуда уехал.

\section{Краткие биографии}

Рассмотрим краткое резюме проведенных интервью.

1. Респондент С. (мужчина, 35 лет) из калмыцкого поселка в Астраханской области, образование среднее специальное: «Занимаюсь ремонтом, в основном ремонтом „под ключ“. Первый раз выехал за пределы республики в 2012 г. Работал в Москве и Санкт-Петербурге. В основном занимался ремонтом квартир в составе бригад. Оплата была по устной договоренности. Жили на объекте или в съемных квартирах. В поиске работы очень помогают родственные и земляческие связи, именно со своего района. Решение о миграции принимали с женой и матерью, братья жены звали на работу».

«Переехали в г. Элисту в 2018 г., потому что старшая дочь поступила в медицинский колледж. Не хочу, чтобы дочь работала, как мы с женой... Жена работает продавцом в продуктовом магазине посменно. Она помогает мне на объекте, штукатурит, красит, мой подмастерье... Стараемся работать вдвоем. Наставляем дочь на учебу, получение образования, потом пусть едет в большой город или на Север... У Марины (жены. - Н. Б.) тетка работает медсестрой на Севере, хотим, чтобы дочь после окончания медколледжа поехала к ней туда. Финансовое положение сложное: оплата съемной квартиры, оплата 2-х кредитов. Младшая дочь живет с мамой в Астраханской области, учится в 4-м классе. Видимся редко, на праздники».

2. Респондент К. (мужчина, 41 год). Районный центр, Республика Калмыкия. Два высших образования. Работает в г. Волгограде, переехал туда после потери работы в г. Элисте на государственной службе. Двое детей, есть две квартиры, работа в Волго- граде с зарплатой более 50 тыс. руб. Возвращаться не планирует, в дальнейшем собирается переезжать в г. Москву. С 2015 г. работал сначала в г. Ростове-на-Дону. Финансовое положение стабильное, хотя оплачивает ипотеку и высылает деньги семье. Жена работает в сфере средне-специального образования. Оплата по трудовому договору. Решение о трудовой миграции принимал самостоятельно.

Влияние трудовой миграции на семейную жизнь большое, на грани развода. Связь с селом остается, поскольку там живут родители.

3. Респондент С. (мужчина, 58 лет). Районный центр, Республика Калмыкия. Работает водителем крана в строительной фирме в г. Москве. Заработки временные. Двое детей. Жена работает сиделкой в г. Элисте, живут у родственников. Дочка младшая учится в школе, в 8-м классе. Старший сын получил заочное образование, работал в г. Твери в фирме по производству кабелей. Финансовое положение сложное. Нацелен на образование для младшей дочери. «Работу нашел через земляков по поселку. В Элисту переезжать не планирую, работать, конечно, буду до пенсии, если здоровье позволит, потому что перенес инсульт... Оплата по трудовому договору, живем либо в общежитии, либо в строительных времянках... Уезжать не хотел, уговаривала жена после потери работы сначала в своем поселке, потом после потери работы в соседнем селе».

4. Респондент Н. (женщина, 59 лет). Районный центр, Республика Калмыкия. Образование среднее специальное. Более 10 лет работает за пределами республики. Работает в г. Липецке нянечкой. «Заработанные деньги тратила на семью, помогала и другим близким родственникам... После смерти отца переехали в город (Элисту). Младший сын получил престижное образование (юридический факультет МГУ). Сейчас помогаю старшему сыну оплачивать кредит, взятый на открытие кофейни. Также приобрела на свои деньги машину старшему сыну, который живет в Элисте со своей семьей». Связи с селом у респондента нет. Решение о миграции принимала совместно с мужем. В настоящее время она вдова: «муж жил с моей мамой, стал часто пить, несколько лет назад умер». Не жалеет о миграции, считает, что помогла в жизни своим детям и пожилой маме. 
5. Респондент Д. (женщина, 32 года). Поселок, Республика Калмыкия. С 2018 г. работает в г. Москве. Разведена, детей нет. Высшее образование. Сначала из поселка семья переехала в районный центр: «у нас в поселке школа маленькая, и чем старше мы становились, тем все меньше учеников оставалось в классе... И мои родители приняли решение переехать в с. Троицкое, где я и мой брат заканчивали школу». Далее для получения высшего образования респондент переехала в Элисту: «когда училась в университете, жила в квартире родного дяди вместе с его дочерью, на выходные уезжала к родителям». В 2014 г. оформила квартиру в ипотеку. Работает в банке в Москве. Живет в съемной квартире с троюродной сестрой. «Развод повлиял на мой отъезд в Москву, почти вся зарплата в Элисте уходила на оплату ипотеки (примерно 15 тыс. рублей в месяц), остаюсь на плаву благодаря помощи родителей». Решение о миграции приняла самостоятельно: «у меня тети еще давно уехали в Москву, студенткой во время летних каникул приезжала в Москву, продавала мороженое». Возвращаться планирует позже для создания семьи.

6. Респондент Э. (мужчина, 52 года). Районный центр, Республика Калмыкия. Высшее образование (заочно). «После армии устроился работать инспектором ГАИ, жил с сестрой на съемной квартире». Миграция за пределы республики после потери работы в г. Элисте: «не прошел аттестацию, когда была реформа в полиции». Работал водителем на Ямале, вахтовым методом: «зарплата была хорошая, купил автомобиль „Фольксваген Джетта“ за 500 тысяч. После определенных проблем и развода автомобиль продал». После рождения дочери (второй ребенок) уехал на заработки в Москву: «помогаю детям, работаю в „Рутакси“" на арендуемой машине. Периодически приезжаю в Калмыкию, в г. Элисте негде останавливаться, еду к матери и сестре в поселок. Помог в ремонте дома. Заработок нормальный, хватает на жизнь, деньги высылаю бывшей жене не каждый месяц, а через раз, покупаю одежду детям. Хочу, чтобы дети получили высшее образование». Нашел работу на Ямале потому, что там работал двоюродный брат. В Москве - через земляков по поселку. Решение о миграции принимали с женой.
7. Респондент А. (женщина, 41 год). Районный центр, Республика Калмыкия. Образование среднее специальное. Четверо детей. Сейчас живет в г. Элисте, работает медсестрой. Развод в миграции. Алименты получает. Заработанные деньги ушли на решение проблем со здоровьем брата. Работала в г. Санкт-Петербурге, г. Москве. За детьми смотрела мама и сестра. Старший сын также имеет опыт работы в Москве, без высшего образования: «бросил [сын] обучение в Калмыцком государственном университете после армии, сейчас работает в Элисте в „Красное и Белое“». Планирует дать высшее образование только одному ребенку, считает его способным: «он отличник в школе, никто ему не помогает с уроками, на кружки не водим». Работа у нее посменная, нарушен режим: «часто работаю в две смены, всегда есть подработка, зарплата хорошая, но все уходит на семью». В 2019 г. впервые за все время вывезла троих младших детей на море в г. Анапу. Связь с селом слабая. Решение о миграции принимала самостоятельно. Практически все родственники отговаривали, поскольку дети были маленькие.

8. Респондент М. (женщина, 37 лет). Маленький поселок, Республика Калмыкия. Работает консультантом-продавцом в магазине косметики в Москве. Детей родила от киргиза, с которым там и познакомилась. Жили в гражданском браке несколько лет. Ездила в Киргизию к мужу. Родители мужа ее не приняли, плохо к ней относились. Дети учатся и живут с ее родителями в поселке в Калмыкии. «Я стараюсь их полностью обеспечивать, хочу, чтобы они получили высшее образование». Решение о миграции принимала самостоятельно: «Сначала приехала работать в г. Элисту, работала в ателье, в Москве тоже начинала работать в ателье». Не видит перспективы для своих детей в поселке.

9. Респондент Н. (мужчина, 43 года). Маленький поселок, Республика Калмыкия. Образование среднее специальное, высшее (заочно). «Учился в училище на сварщика, потом забрали в армию, после армии поступил на работу в ППС, потом работал во вневедомственной охране. После реформы полиции потерял работу». Поехал сначала один на работу в Чукотский автономный округ. На тот момент у него было двое де- 
тей. Затем забрал семью, там родились еще трое детей. Работает участковым: «Учился заочно, в 2016 г. получил диплом юриста в Современной гуманитарной академии». Приезжает в Калмыкию редко, после возвращения хочет заниматься сельским хозяйством, «купить точку». Жена не работает. Собственности нет, купили только автомобиль в кредит. Автомобиль стоит у родственников в гараже. Связь с селом сильная.

10. Респондент Т. (женщина, 64 г.). Районный центр, Республика Калмыкия. После продажи дома в своем селе купила двухкомнатную квартиру в г. Элисте. С мужем развелась, трое детей. Старший сын жил с отцом в квартире свекрови, которая тоже переехала в город. Более 13 лет работала сиделкой и швеей в Москве. Сначала работала сиделкой с проживанием. Смотрела в основном за пожилыми женщинами. Меняла работу после смерти хозяев. Работу находила через родственниц и знакомых. Однако примерно после 6-7 лет такой работы, поняла, что самой становится тяжело работать: «ухудшается зрение, поднимается давление», «нет больше сил тягать этих пожилых женщин». «Жила в съемной комнате в двухкомнатной квартире, которую сдавала землячка». Заработок отправляла сыновьям на содержание их семей, «всегда отправляла денежку внукам». Оплатила свадьбу среднему сыну. С 2016 по 2018 гг. жила с сестрой в однокомнатной квартире, сестра приехала после потери работы: «выгнали как пенсионерку». Помогала землячкам, занимала деньги, однако некоторые затем ей не возвращали долги. По приезде домой оплачивала долги по коммунальным услугам в своей квартире, в которой жил один из сыновей, раз в несколько лет делала косметический ремонт в квартире. Ее пенсию получал младший сын, который тратил ее по своему усмотрению. Вернулась в 2018 г., живет в своей квартире, средний сын уехал на заработки на Север. Невестка с внуками то уезжают в село к ее родителям, то здесь живут. Связи с селом нет, живет в г. Элисте.

\section{Комментарий}

На основе изложенного выше материала можно сделать некоторые выводы. В первую очередь о влиянии образования на «престижность работы» в трудовой миграции. Анализ результатов проведенных глубинных интервью показал, что уровень образования и квалификации влияет на финансовое положение респондентов. У peспондентов с высшим образованием финансовое положение оценивается ими как стабильное. У большинства респондентов со средне-специальным образованием финансовое положение оценивается как сложное. Также отметим, что в исследовании важно было выявить, как принималось решение о миграции: самостоятельно или нет. В большинстве рассмотренных случаев решение о миграции принималось и обсуждалось с женой или мужем, близкими родственниками.

Только пара рассмотренных случаев показывает относительно положительный экономический эффект. В большинстве же рассмотренных историй миграция оказывает временный экономический эффект. Только у двоих респондентов есть желание жить в своем родном селе или поселке, у одного желание заниматься сельским хозяйством. У большинства мигрантов утеряны связи с родным селом или поселком, полностью отсутствует желание вернуться туда.

Практически все опрошенные респонденты проходили два этапа миграции: переезд из сельского поселения в столицу республики, а затем миграция за пределы республики. При этом трудовая миграция за пределы республики и продажа дома в своем поселке или селе позволила многим из опрошенных в дальнейшем приобрести жилье в столице республики, делая невозможным возвращение к жизни в сельской местности.

Некоторые примеры показывают, как миграция становится семейной стратегией. Либо дети наших респондентов уже уехали, либо респондент предполагает, что, получив образование, его дети уедут на заработки в другие регионы.

Любопытно отметить, что на миграцию некоторых респондентов повлияла Реформа МВД России, начатая в 2011 г., в результате которой численность сотрудников в стране сократилась на 20 \% [Евсейчук 2013].

\section{Обсуждение}

Глубоко причины миграции в проведенном исследовании мы не рассматривали, поскольку очевидно: в основе принятия решения о трудовой миграции - экономические причины. Одним из таких факторов, характерных для опрошенных респонден- 
тов, является необходимость оплачивать ипотеку или потребительские кредиты.

На большинстве респондентов лежит ответственность за благополучие домочадцев. При этом важно отметить, что миграционные циклы тесно соотносятся с важнейшими этапами жизненного цикла - женитьбой, разводом, рождением детей, женитьбой сыновей или выдачей замуж дочерей. Для части респондентов решение о миграции связано с определенными этапами взросления детей. Н. Н. Жидкевич отмечает, что очень часто первый отъезд семейного отходника на заработки связан с переломными моментами в жизни детей: рождение начало обучения в школе - поступление в институт - вступление в брак. Высшее образование требует от семей, дети в которых достигли соответствующего возраста, крупных финансовых вложений [Жидкевич 2016: 78].

Для всех респондентов миграция была вынужденной мерой, они терпят большое количество неудобств: социально-бытовые (жизнь в съемных квартирах, комнатах, строительных временных сооружениях, холодных недостроенных объектах; много времени тратят на дорогу на работу); физические (изматывающий график работы, тяжелый физический труд в сфере строительства, при уходе за пожилыми и больными); психологические (регулярный отрыв от семьи, потеря прежнего, возможно, более «престижного» социального статуса, переживания за больных родственников, пожилых родителей, чувство вины за неучастие в жизни детей и др.).

Следует отметить, что миграции формируют новый контекст семейно-брачных отношений: браки приобретают признаки «гостевого брака», в семье меняются гендерные роли, например, когда на заработки уезжает женщина. Согласимся с мнением С. Д. Джанызаковой, что понимание гендера в миграционном процессе, при котором женщинам отводилась роль хранительниц

\section{Литература}

Блинова 2011 - Блинова М. С. Миграции населения: подход социологов Чикагской школы // Вестник Московского университета. Серия 18. Социология и политология. 2011. № 4. 2011. С. 172-190. очага, а мужчинам - добывание средств к существованию, в том числе и путем миграции, уходит в прошлое и смещается к «переносу» роли и обязанностей мужчин на плечи женщин. Они занимают положение трудоспособных участников рабочей миграции, наравне с мужчинами входят на рынок труда [Джанызакова 2017: 217]. Трансформируется или подменяется роль бабушек или дедушек, зачастую выполняющих функции выехавшего родителя. При этом миграции могут быть толчком к ухудшению отношений и разводу. В то же время есть случаи, когда сложные семейно-брачные отношения или развод приводят к миграции.

Значительное влияние приобретают горизонтальные социальные сети: на решение о миграции влияют родственники или знакомые, имеющие опыт миграции; земляческие и родственные отношения помогают с поиском жилья и работы; оказывают финансовую поддержку в случае потери работы (занимают деньги в долг, делятся продуктами).

\section{Заключение}

К сожалению, отмечаем, что миграция для сельских жителей республики стала повседневностью. Комплекс миграционных решений представляется гибкой семейной стратегией. Опыт работы на выезде становится инструментом экономической стратегии и мобильности - люди покупают жильё в городе, заработанные деньги используются для помощи в реализации жизненных планов детей. Миграция родителей становится ориентиром для будущих миграций их детей. Однако важно отметить, что полученные результаты позволяют фиксировать в социальном профиле сельских трудовых мигрантов активных личностей, высоко мотивированных к труду, сочетающих стремление к достойному уровню жизни с умением приспосабливаться к напряженным условиям труда и быта в отрыве от дома и семьи.

Голенкова, Сушко 2016 - Голенкова 3. T., Суико П. Е. Социальная мобильность в контексте миграционных биографий россиян // Социологические исследования. 2016. № 12. C. $95-104$.

Джанызакова 2017 - Джанызакова С. Д. «Жить 
или проживать?»: индивидуальные миграционные стратегии женщин-мигранток в Томске // Вопросы истории, археологии, политических наук и регионоведения: сб. материалов XIII Всерос. науч. конф. студентов, магистрантов, аспирантов и мол. ученых (г. Томск, 24-26 апр. 2017 г.). Вып. 13, т. 2. Томск: Изд-во Том. ун-та, 2017. С. 211-217.

Жидкевич 2016 - Жидкевич Н. Н. Социальный портрет современного российского отходника // Журнал социологии и социальной антропологии. 2016. № 1. С. 73-89.

\section{References}

Blinova M. S. Migration: approach of the Chicago School sociologists. Moscow State University Bulletin. Series 18. Sociology and Political Science. 2011. No. 4. Pp. 172-190. (In Russ.)

Dzhanyzakova S. D. 'Full or part residents?': individual migration strategies of female migrants in Tomsk. In: Issues of History, Archaeology, Political Science, and Regional Studies. Conf. proc. (Tomsk; April 24-26, 2017). Vol. 13. Part 2. Tomsk: Tomsk State University, 2017. Pp. 211-217. (In Russ.)

Evseychuk D. Militia reformed: correcting mistakes. Tomskie novosti. Online newspaper. Posted on July 25, 2013. Available at: http://tomsk-
Евсейчук 2013 - Евсейчук Д. Милицейская реформа: работа над ошибками [электронный pecypc] // Томские новости. 25.07.2013 г. URL: http://tomsk-novosti.ru/militsejskayareforma-rabota-nad-oshibkami/ (дата обращения: 08.05.2020).

Соснина 2012 - Соснина И. В. Социальные аспекты интеграции трудовых мигрантов [электронный ресурс] // Современные проблемы науки и образования. 2012. № 3. URL: http://science-education.ru/ru/article/ view?id=6441 (дата обращения: 08.05.2020).

novosti.ru/militsejskaya-reforma-rabota-nadoshibkami/ (accessed: May 8, 2020). (In Russ.)

Golenkova Z. T., Sushko P. E. Social mobility in the context of migration biographies of Russia. Sociological Studies (Socis). 2016. No. 12. Pp. 95-104. (In Russ.)

Sosnina I. V. Social aspects of integration of labor migrants. Modern Problems of Science and Education. 2012. No. 3. Available at: http:// science-education.ru/ru/article/view? $\mathrm{id}=6441$ (accessed: May 8, 2020). (In Russ.)

Zhidkevich N. N. Domestic temporary labor migrants in Russia: a social portrait. The Journal of Sociology and Social Anthropology. 2016. No. 1. Pp. 73-89. (In Russ.) 